\title{
Progesterone regulates corticosterone elevation and alterations in spatial memory and exploratory behavior induced by stress in Wistar rats"
}

\author{
La progesterona regula la elevación de corticosterona y las alteraciones en \\ memoria espacial y conducta exploratoria inducidas por estrés en ratas Wistar
}

Received: february 12th, 2010 ～Reviewed: august 13th, 2010 | Accepted: september 1st, 2010

\author{
YOLANDA DiAZ-BURKE** \\ Claudia Elena GonZAlez-SANDOVAL ${ }^{* * *}$ \\ Universidad de Guadalajara, Jalisco, Mexico \\ CARlos EdUARdo VAlEnCIA-AlFONSO **** \\ Netherlands Institute for Neuroscience, Amsterdam, \\ The Netherlands \\ Miguel HUERTA** \\ XóChITL TRUJILLO ${ }^{* * * * * * *}$ \\ Universidad de Colima, Colima, Mexico \\ LOURDES DIAZ ${ }^{\text {********* }}$ \\ Centro de Investigación y Asistencia en Tecnología y \\ Diseño del Estado de Jalisco. Jalisco, México \\ JOAQUÍN GARCÍA-ESTRADA ${ }^{* * * * * * *}$ \\ Centro de Investigación Biomédica de Occidente, \\ IMSS-Jalisco. Jalisco, Mexico \\ SONIA LUQUÍN ${ }^{* * * * * * * * *}$ \\ Netherlands Institute for Neuroscience, Amsterdam,
}

The Netherlands

Para citar este artículo. Díaz-Burke, Y. et al. (2010). Progesterone regulates corticosterone elevation and alterations in spatial memory and exploratory behavior induced by stress in Wistar rats. Universitas Psychologica, 9 (3), 627-640.

\footnotetext{
* Original research article. The first two authors should be considered "first author" since they both contributed equally to the paper. Funding provided by 1 . Simorelos 19990302034 for SL. 2. CONACYT 35384-M for SL. 2. SRE México. Cuauhtemoc II for Ceva. 3. Promep 103.5/03/2175 for YDB

*** E-mail: ydiazb@prodigy.net.mx

****E-mail:mqcclaudia@yahoo.com.mx

******* E-mail: valenciacarlose@gmail.com

********mail: rosio@cgic.ucol.mx

*********E-mail: xtrujillo@ucol.mx

**********mail:1diaz@ciatej.net.mx

********** E-mail: jgarciae@cencar.udg.mx

************** E-mail: sonialu@prodigy.net.mx
}

\begin{abstract}
A B S T R A C T
The hippocampus is sensitive to high levels of glucocorticoids during stress responses; it suffers biochemical and cellular changes that affect spatial memory and exploratory behavior, among others. We analyzed the influence of the neurosteroid progesterone (PROG) on stress-induced changes in urinary corticosterone (CORT) levels, spatial memory and exploratory behavior. Castrated adult male rats were implanted with PROG or vehicle (VEHI), and then exposed for ten days to chronic stress created by overcrowding or ultrasonic noise. PROG and CORT levels were assessed in urine using highperformance liquid chromatography (HPLC). Implanted PROG inhibited the rise of stress-induced CORT, prevented spatial memory impairment in the Morris water maze, and eliminated increased exploratory behavior in the hole-board test. These results suggest a protective role of PROG, possibly mediated by its anxiolytic mechanisms, against corticosteroids elevation and the behavioral deficit generated by stressful situations.

Keywords authors

Progesterone, Stress, Corticosterone, Spatial Memory, Ultrasonic Vocalizations, Overcrowding.

Keywords plus

Rats-Psychology, Progesterone, Corticosterone, Stress (Psychology).
\end{abstract}




\section{RESUMEN}

El hipocampo es sensible a altos niveles de glucocorticoides. Durante la respuesta de estrés, esta estructura sufre cambios bioquímicos y celulares que afectan funciones tales como la memoria espacial y la conducta exploratoria, entre otras. En este estudio analizamos la influencia del neuroesteroide progesterona (PROG) sobre los cambios inducidos por estrés en corticosterona (CORT) urinaria, memoria espacial y conducta exploratoria. Se implantó PROG o vehículo (VEHI) a ratas macho adultas castradas y se les expuso a estrés crónico por hacinamiento o ruido ultrasónico durante 10 días. Se evaluaron niveles de PROG y CORT en orina usando cromatografía líquida de alta resolución (HPLC). Los implantes de PROG inhibieron el incremento de CORT inducido por estrés, previnieron el detrimento de la memoria espacial en el laberinto acuático de Morris y eliminaron el incremento en la actividad exploratoria en la prueba del campo de agujeros. Estos resultados sugieren un efecto protector de la PROG, posiblemente mediado por los mecanismos ansiolíticos de la hormona, contra la elevación de corticoesteroides y el déficit conductual generado por las situaciones estresantes. Palabras clave autores

Progesterona, estrés, corticosterona, memoria espacial, vocalizaciones ultrasónicas, hacinamiento.

Palabras clave descriptor

Ratas-psicología, progesterona, corticosterona, estrés psicológico.

\section{Introduction}

It has been shown that stress stimulates the hypothalamus-pituitary-adrenal (HPA) axis increasing the blood levels of circulating glucocorticoids (GCs), especially after prolonged exposure (McEwen, 2000). As a result of sustained GCs rise, the hippocampus suffers functional abnormalities related to atrophy of apical dendrites in the CA3 area, and neurogenesis suppression in the dentate gyrus (Kim \& Diamond, 2002). Consequently, a deficient performance in hippocampal-related tasks is found, such as in declarative, episodic, contextual, and spatial memory (McGaugh et al., 1995). Additional behavioral findings show also that stress influences negatively the motivation for exploratory behavior of a novel environment (Raber, 1998).

In addition to GCs rise during chronic stress, an intracerebral increase of neurosteroids concentration takes place, possibly as a protective mechanism (Obut, Ovsyukova, \& Cherkasova, 2004). Increased levels of neurosteroids pregnenolone (PREG) and progesterone (PROG) have been re- ported in response to $\mathrm{CO} 2$ stress (Shimada \& Yago, 2000), while forced swimming stress was able to elevate PREG and allopregnenolone (Vallée, Rivera, Koob, Purdy, \& Fitzgerald, 2000). Particularly, PROG increase has been observed after several stress conditions including chronic social stress, acute electric shocks and maternal separation (K Shimada \& Yago, 2000). In general, the protective role of these neurosteroids is related to their impact on nuclear receptors that modulate ionic channels, on membrane-receptors such as GABAA, glycine, glutamate (Higashi, Takido, \& Kazutake Shimada, 2005), and on sigma- 1 receptors, which control the intracellular uptake of calcium. Therefore, they are considered to be involved in neuroprotection, learning, memory, and stress response (Maurice, Urani, Phan, \& Romieu, 2001).

The protective role of PROG has been questioned by experiments showing cognitive impairment related to PROG levels (Türkmen, Löfgren, Birzniece, Bäckström \& Johansson, 2006). However, other researchers (Maki, Zonderman \& Resnick, 2001) have found opposite results in which PROG replacement therapy caused a beneficial effect on the verbal memory of older non demented women. Likewise, pregnant rats showed less perseveration of previously learned information while locating a new position of the escape platform in the Morris water maze test (Bodensteiner, Cain, Ray \& Hamula, 2006). Additionally, in aged oophorectomized rats, the long-term treatment with estrogen and PROG enhanced information acquisition in spatial memory tasks (Frye, Duffy \& Walf, 2007), PROG can also revert memory impairment caused by cortisol administration (Kuhlmann \& Wolf, 2005). These results show that PROG effects on cognitive functions may not always be negative and may depend on the neurophysiologic context.

One of the most important behavioral effects of PROG is related to changes in anxiety levels (Obut et al., 2004). In rats, PROG was able to suppress immobilization stress effects (Le Mellédo \& Baker, 2004), and showed anxiolytic effects in the elevated plus maze test (Rhodes \& Frye, 2005). Moreover, experimentally induced anxiety in rats has been related with low PROG concentrations 
(Zuluaga et al., 2005). On the other hand, there is also evidence relating different levels of PROG with negative ansiogenic effects. Women in the mid-luteal phase (when both progesterone and estrogen levels are relatively high) showed enhanced adrenocorticotropic hormone in response to exercise-induced stress (Altemus, Roca, Galliven, Romanos \& Deuster, 2001). Additionally, the continuous exposure of animals for 48 hours to PROG caused them enhanced anxiety in the elevated plus-maze (Gulinello \& Smith, 2003). In control circumstances PROG can also produce unexpected collateral effects, for example; although PROG diminished alcohol consumption in socially isolated rats, it also caused an increased consumption of liquids in unstressed rats. Moreover, PROG protected against immune depression in rats stressed by immobilization, however, it also caused immunological suppression in unstressed rats (Mediratta et al., 2003). These results suggest that PROG anxiolytic properties are still to be clarified, especially regarding the type of stress they act on.

Within anxiety research, several methods have been used to generate stress in animals, however, social stress models are closer to human situations in which stressful stimulus normally comes from other individuals (Henry et al., 1993). These models are equally effective in raising GCs as consequence of HPA-axis hyperactivity, and causing neuronal alterations in the hippocampus and its associated functions. In social environments rodents emit ultrasonic vocalizations (USVs) in the range of $18-24 \mathrm{kHz}$ artificial sound waves within this range can be used. Consequently, artificial sound waves within this range can be used to induce social stress in these animals (Commissaris et al., 2000). Overcrowding is another social condition that generates stress, and induces alterations in several cerebral neurotransmitters, and dendritic atrophy of pyramidal neurons in the CA3 region of the hippocampus (Magariños, Verdugo \& McEwen, 1997).

So far, the preventive and protective actions of PROG against the physiological and cognitive consequences of socially induced stress have not been explored. We intended to establish the pos- sible neuroprotective influence of PROG implants on GCs levels, memory, and exploratory behavior, in rats exposed to artificial USV s or overcrowding.

\section{Methods}

\section{Animals}

Sixty male Swiss-Wistar rats (250-289 g, 60 days old) from our in-house colony were divided in two groups - control and experimental. They were housed in clear polycarbonate cages and kept in a dark/light cycle of $12 / 12$ hours, at $22^{\circ} \mathrm{C}$ and $55 \%$ relative ambient humidity. They had free access to balanced food (Ralston rations, USA) and potable water throughout the experiment. All studies were performed in accordance with the NIH guidelines for the care and use of laboratory animals.

\section{Surgical procedures}

Castration was done under short anesthesia during which testicles were detached following a torsioninduced thrombosis. The incision was closed and animals were then left to recover for 21 days. After this period each rat was again anesthetized and then implanted with one permeable silicone tube (Sani-Tech) containing vehicle sesame oil (VEHI), or $8 \mathrm{mg}$ of progesterone dissolved in vehicle (PROG) (Sipos \& Nyby, 1996). A dorsal incision in the skin between the shoulder blades was practiced to create a subcutaneous tunnel that housed the implant (18mm long, 3.12 mm internal diameter, and 3.92 external diameter) designed for prolonged delivery of the substances. Seven days after implantation, the animals were subjected to two different stress conditions.

\section{Stress exposure}

Rats were implanted with VEHI $(n=30)$ or PROG $(n=30)$. In each set, subgroups of 10 rats were subjected to three different lodging conditions for ten days: 1) Control: Standard conditions of vivarium described above, $240-\mathrm{cm} 2 /$ rat with ordinary environmental noise. 2) Overcrowding (OVCR): 
Standar conditions but restricted space with 45 $\mathrm{cm} 2 /$ rat and normal environmental noise. 3) USVs noise (NOISE):, Standard conditions and normal space with but exposed for eight hours/day to 22 $\mathrm{kHz}$ tones in 80-90 dB waves, with intermittent random intervals of 30 minutes each.

\section{High performance liquid chromatography}

To quantify the corticosterone and PROG concentrations in urine samples by HPLC, urine was collected every 48 hours, starting the day prior to the beginning of the ten day stress period. Retention times and size of the chromatographic profile were standardized with known quantities of progesterone or corticosterone dissolved in methanol. For the urine analysis, we followed the procedure developed by Juricksay and Telegdyde (2000) with slight modifications. In brief, to retain the steroids contained in urine, $1 \mathrm{ml}$ urine was passed through a C18 extraction cartridge (Waters Assoc., Milford, MA USA); then, it was eluted from the cartridge into Teflon-coated cap glass vials containing $5 \mathrm{ml}$ methanol, which was evaporated afterwards by means of a nitrogen flow in a $40-45^{\circ} \mathrm{C}$ bath before adding $4 \mathrm{ml}$ buffer acetate at $\mathrm{pH}$ 4.6. This solution was incubated at $37^{\circ} \mathrm{C}$ for 48 hours with $50 \mu \mathrm{l}$ of glucoronidase enzyme from Helix pomatia (Merck KGsA, Darmstadt, Germany). After incubation, steroids were retained again in $\mathrm{C} 18$ cartridges and eluted with $5 \mathrm{ml}$ methanol. The volume was concentrated to $100 \mu \mathrm{l}$ using a nitrogen flow for $10-\mu \mathrm{l}$ samples which were extracted and injected into the liquid chromatograph (Thermo Finnegan), the samples were then passed through a CP SIL 5CB apolar column (Altech), measuring $30 \mathrm{~mm}$ x 0.32 x $0.25 \mu \mathrm{m}$ at $30^{\circ} \mathrm{C}$, this column is used for amines, hydrocarbons, pesticides, phenols and sulfured compounds. The total time of chromatographic analysis was 35 minutes.

\section{Exploratory activity in the Hole-board}

Behavioral studies started the day after completion of stress exposure. The Hole-board test was used to analyze the rats' exploratory activity in a novel place, as well as their excitability and anxiety. This test consisted of a hollow black acrylic cube of $60 \mathrm{x}$ $60 \times 60 \mathrm{~cm}$ with a platform $5 \mathrm{~cm}$ above the entire floor surface, pierced by 36 holes of $2.5 \mathrm{~cm}$ diameter (hole field), distributed in a 6x6 arrangement. This field was divided by an imaginary line into a peripheral zone (the peripheral line of holes in the platform), and a central zone of $4 \mathrm{x} 4$ holes. All animals were tested daily between 9:00 a.m. and 11:00 a.m. Each rat was placed in the center of the field to begin its exploration, and we video-recorded its behavior for ten minutes. Then, we reviewed the videotape to register the following parameters: time spent in the central and peripheral zones, total time of mobility or immobility, number of visits to central and peripheral holes, total number of holes visited, and relative frequency of visits (number of visits/minute). A hole was considered visited when a rat inserted its head into the hole, behind the level of its eyes (Lordi, Patin, Protais, Mellier $\&$ Caston, 2000).

\section{Morris water maze (MWM)}

We followed the MWM procedure used by De Quervain et al (de Quervain, Roozendaal, \& McGaugh, 1998). On the first day, the rats had 8 training trials $(60 \mathrm{~s}$ duration and $60 \mathrm{~s}$ inter-trial interval) in each of which they were required to locate a cylindrical black platform $(24 \times 10 \mathrm{~cm})$ hidden under the water. The platform had a fixed position throughout the study at the center of one of the four imaginary quadrants of the black round swimming pool (180 $\mathrm{cm}$ in diameter, $40 \mathrm{~cm}$ deep) filled with warm water $\left(23 \pm 3^{\circ} \mathrm{C}\right)$ to a depth of 25 $\mathrm{cm}$. The rats were placed at randomly selected quadrants in the water, facing the center of the pool. Once the rat found the platform, it was allowed to remain there for ten seconds. If a rat failed to find the platform within the 60 seconds of the trial, it was manually guided to it, and allowed to remain there for ten seconds, before being returned to its holding cage. Twenty-four hours later a memory retention test was performed, which consisted of one 60-seconds trial with no escape platform, starting from a quadrant adjacent to the one where the 
platform was located during training. All MWM sessions were conducted between 9 am and 3 pm on each day, and all rats were trained the same day in a closed, sound-proofed room lit with diffused, attenuated light. The fixed furniture in the experimental room was used as spatial cues.

All trials were video-recorded to manually register the time of latency, distance navigated to reach the platform, velocity, and time spent in each quadrant, all data was blind analyzed. While the rats were in the pool, experimenters were kept out of their visual field. In the memory trial the number of crossings with the place of the absent platform, and time spent in the platform quadrant were measured.

\section{Statistical analyses}

After testing for normal distribution of the data, mixed ANOVAS analysis for repeated measures with Bonferroni Post-hoc test were applied to compare hormonal measures through the 10 days stress-period, and 8 training MWM trials, and multivariate ANOVAS for the MWM test, and the Hole-Board test, also with Bonferroni Post-hoc analysis. To define the differences as significant, we used a confidence level of $p<0.05$.

\section{Results}

\section{Urinary progesterone levels}

We used high-performance liquid chromatography (HPLC) to measure the quantity of urinary progesterone released after insertion of the subcutaneous implant. Results indicated a high, constant and stable release of this hormone during the 10 days stress period in PROG compared to VEHI (Figure 1). Data were analyzed with a mixed $2 \times 3$ x 6 multivariate ANOVA with days as within subject factor, implant (PROG or VEHI) and groups (Control, OVCR, and NOISE) as between subject factors, with epsilon-corrected degrees of freedom (Greenhous-Geisser). The impact of the implant factor was highly significant $\left(\mathrm{F}_{(1,18)}=3449.52, p<\right.$

FIGURE 1

Effective and constant liberation of PROG implants

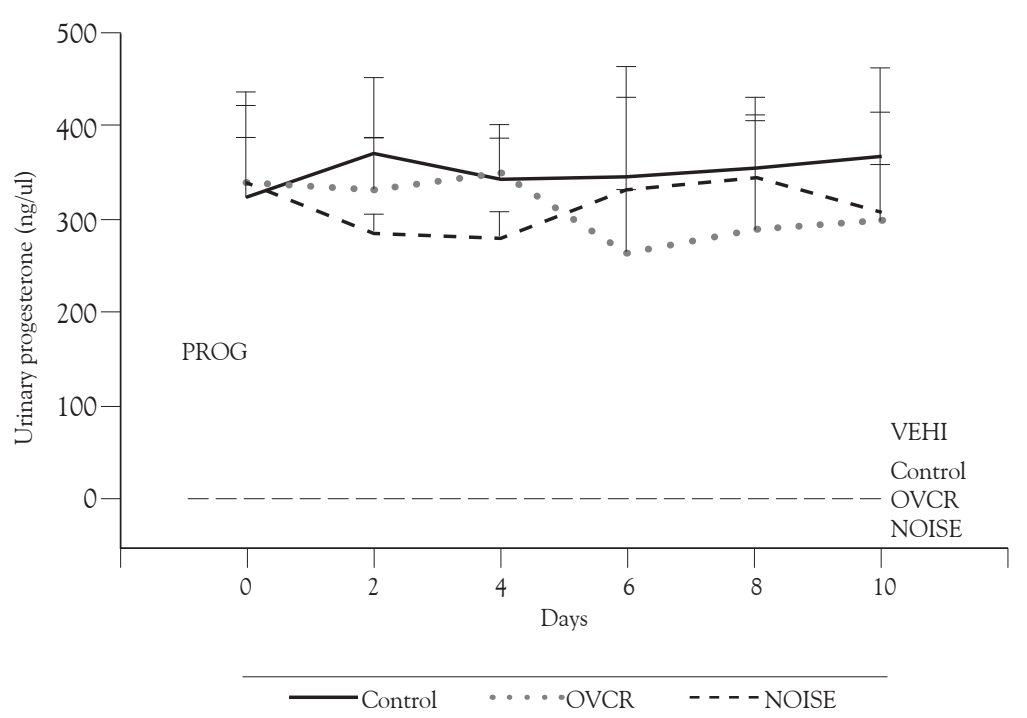

Day 0 indicates the baseline, one day before the beginning of the ten-day stress period. Notable supra-physiological PROG levels were constantly released from the hormone implant. Progesterone levels under VEHI implants were significantly lower and are represented by the dotted line. PROG release rate after the implant was not influenced by the different stressful situations or through time. Bars show standard deviation.

Source: own work. 
0.001) due to elevated levels of PROG detected in hormone-implanted animals $(328.13 \pm 11.79 \mathrm{ng} /$ $\mu \mathrm{l})$, compared with VEHI animals $(0.344 \pm 3.94$ $\mathrm{ng} / \mu \mathrm{l})$. The stress factor did not have an influence in this liberation $\left(F_{(2,18)}=4.91, p>0.05\right)$ since there were no significant differences between the level of PROG liberated under Control (166.65 $\pm 4.83 \mathrm{ng} / \mu \mathrm{l})$, OVCR $(157.25 \pm 6.79 \mathrm{ng} / \mu \mathrm{l})$ and NOISE $(158.86 \pm 4.54 \mu \mathrm{g} / \mathrm{ml})$. The interaction between both factors was also non significant $\left(F_{(2,18)}=4.81, p>0.05\right)$

\section{Corticosterone urinary levels}

Urinary CORT was also quantified with HPLC in order to estimate stress levels in each condition. The data were analyzed with the same statistic procedure used for PROG. Factors implant $\left(F_{(1,18)}\right.$ $=23.32, p<0.001)$, stress $\left(F_{(2,18)}=115.79, p<\right.$ $0.001)$ and days $\left(F_{(3.07,55.21)}=21.66, p<0.001\right)$ showed a significant impact, as well as the stressimplant interaction $\left(F_{(2,18)}=6.29, p<0.05\right)$. The differences are mostly due to the influence of the group factor which had a high partial Eta square $(\eta$ $=0.928$ ), suggesting that a big part of the changes are due to stress conditions disparity (Figure 2). In coherence, NOISE showed a higher level of urinary CORT $(214.92 \pm 4.11 \mathrm{ng} / \mu \mathrm{l})$ compared to OVCR $(144.69 \pm 3.18 \mathrm{ng} / \mu \mathrm{l})$, and both stress factors had more CORT as Control $(132.97 \pm 3.79 \mathrm{ng} / \mu \mathrm{l})$ (Figure 2). Bonferroni Post-hoc test showed that NOISE was higher than OVCR $(p<0.001)$ and Control $(p<0.001)$, but OVCR was not different from Control. This last finding might be due to the fact that OVCR with PROG implants had a similar CORT level as the Control group (see below). Nevertheless, the results show that both stressful conditions are able to stimulate the HPA axis, and that noise had more impact than overcrowding.

The implant factor $(\eta=0.564)$ also showed an important impact as a result of the elevated CORT found in VEHI-implanted rats (175.67 $\pm 4.36 \mathrm{ng} / \mu \mathrm{l})$ compared to those implanted with PROG $(152.71 \pm 3.37 \mathrm{ng} / \mu \mathrm{l})$, which suggest that PROG had, in a general way, an inhibitory role on the stress-related CORT increase.
Subsequent mixed $2 \times 6$ ANOVA analyses were conducted in order to know the conditions under which the differences have their main effect. The ANOVA was carried out isolating the different stress groups, with days as within subjects factor, and implant as between subject factor. In absence of stress (Control group), the results showed no influence of the implant $\left(F_{(1,6)}=0.344, p>0.05\right)$ and therefore no differences between the groups with VEHI $(134.67 \pm 4.11 \mathrm{ng} / \mu \mathrm{l})$ or PROG $(131.26 \pm$ $4.23 \mathrm{ng} / \mu \mathrm{l})$, indicating that implant content does not influence the levels of this hormone in normal conditions (Figure 2A). On the other hand, the same analysis for overcrowded groups proved that the implant had a significant impact $\left(F_{(1,6)}=44.79\right.$, $p<0.001)$ and in coherence, those subjects with PROG had a stable CORT production (122.39 \pm $4.32 \mathrm{ng} / \mu \mathrm{l})$ similar to Control, while in those with VEHI the hormone level was increased (166.99 \pm $4.71 \mathrm{ng} / \mu \mathrm{l})$. This suggests an inhibitory effect of the hormone on the GCs rise (Figure 2B). However, in groups of rats stressed by ultrasonic noise, the implant had a non significant effect $\left(\mathrm{F}_{(1,6)}=3.48\right.$, $p>0.05)$, and VEHI rats showed similar CORT levels compared to those with PROG implant (Figure 2C). Nevertheless, it is possible to observe that in NOISE rats with VEHI implant, CORT started rising on the second day and maintained this level until the end of the experiment, whereas rats in the PROG group showed a retardation in the CORT rise (up to day 4), then reversed the increment of GCs level at the end of the ten-day stress period (Figure 2C), this suggests that the absence of significant differences could only be due to the averaged stress days, but that the dynamic and distribution of the CORT levels were different in this period of time due to the PROG implants.

\section{Learning in Morris water maze}

During the training phase, regardless of the type of implant and the stressful situation, all rats showed similar performances based on the latency of escape, the time spent in the platform quadrant and in the opposite quadrant, total distance, and velocity. In all cases, a typical learning curve resulted of 
FIGURE 1

Effective and constant liberation of PROG implants

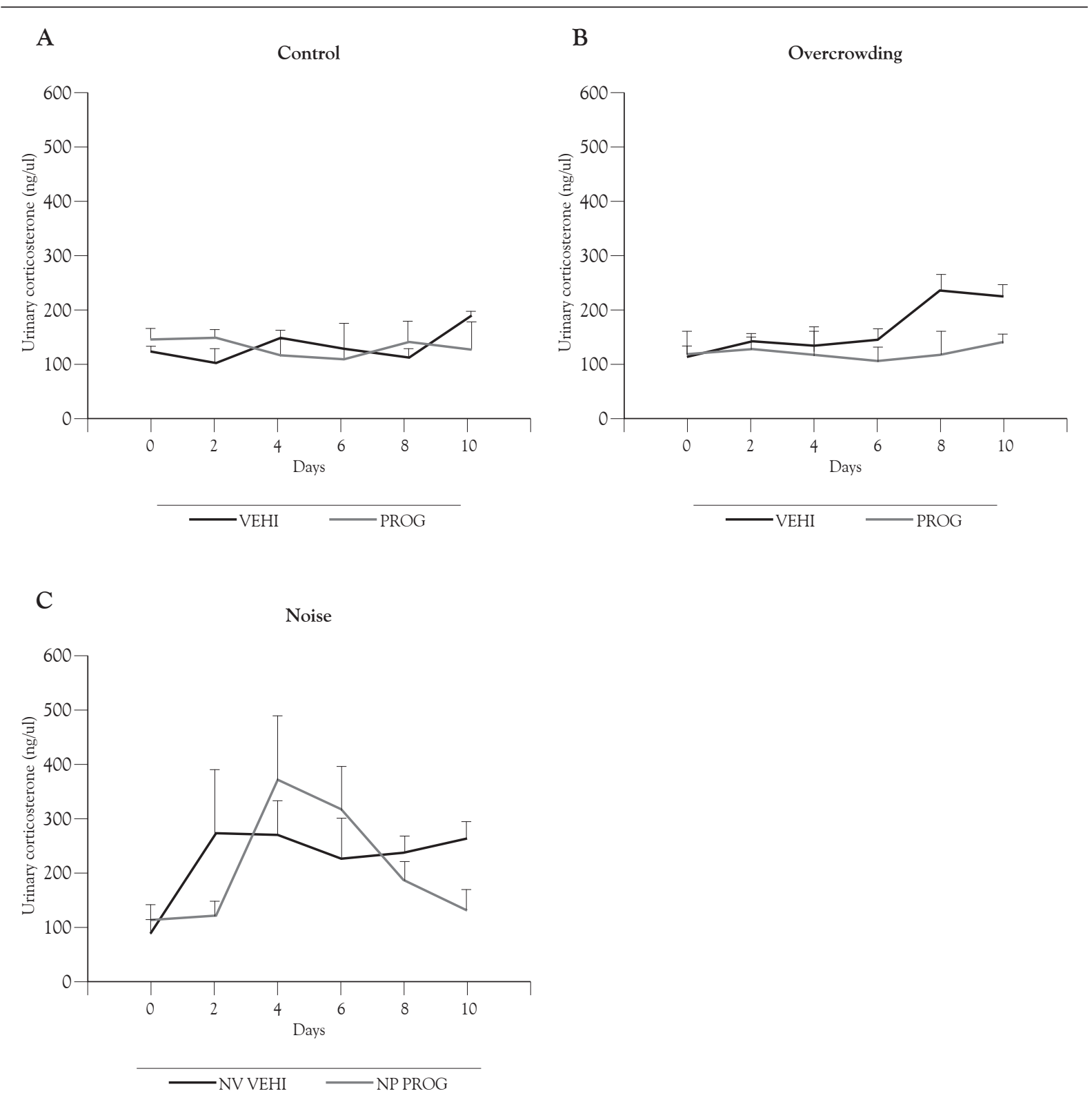

A). There were no differences among the two implant control groups. B) Overcrowded rats with PROG implant maintained stable CORT levels similar to control groups while the same stress condition induced an elevation in CORT for VEHI implanted rats. C) Rats exposed to noise showed a significant elevation compared to control stress conditions. However a delay and reverse effect of PROG implants in the noise-stressed group can be observed compared to the VEHI group. Bars show standard deviation.

Source: own work.

unstressed and stressed animals at the end of the eight trials. The comparison among these curves showed no statistical differences among them, when they were analyzed through a mixed $2 \times 3 \times$ 
8 multivariate ANOVA with trials (8) as within subjects factor, implant (PROG or VEHI) and stress (Control, OVCR, and NOISE) as between subject factors.

\section{Memory consolidation}

In the second stage of this test, the rats tried to find the (now absent) platform based on the experience previously acquired during training phase, therefore, crossing (cr.) of their swimming path with the previous location of the platform was also assessed. The data were analyzed using a 2 × 3 multivariate ANOVA with stress and implant as between factors and no significant differences for any factor in the previous MWM measurements. However, there was an important effect in the number of times that the rat crossed the place where the platform was previously located, which assesses how strongly the rat remembered this specific place. For this parameter, the implant $\left(F_{(1,42)}=14.67, p<0.001\right)$, stress $\left(F_{(1,42)}=5.09, p<0.01\right)$ and the interaction between them $\left(F_{(2,42)}=5.611, p<0.01\right)$ showed statistically significant differences (Figure 3 ).

A Bonferroni post-hoc test showed that OVCR $(p<0.05)$ and NOISE $(p<0.05)$ were significantly higher than Control, but no different between them $(p>0.05)$. The type of implant had no influence in the Control rats $(1.86 \pm 0.25 \mathrm{cr}$.) and VEHI $(1.71 \pm 0.25 \mathrm{cr}$. $)$ maybe due to the similarity in their CORT levels. However, the implant content had an important influence in the overcrowded animals, where PROG $(1.57 \pm 0.22 \mathrm{cr}$. $)$ and VEHI $(0.57 \pm 0.24 \mathrm{cr}$. $)$ were significantly different. The same was true for NOISE PROG $(1.86 \pm 0.25$ cr.) and VEHI $(0.35 \pm 0.23 \mathrm{cr}$.) (Figure 3). Posterior one way-ANOVA analysis, isolating the type of stress and with implant as fixed factor, showed no significant differences between PROG and VEHI in Control stress $\left(F_{(1,13)}=0.14, p>0.05\right)$, and the importance of the implant effect in OVCR $\left(F_{(1,13)}\right.$ $=12.25, p<0.005)$ and NOISE $\left(F_{(1,13)}=15.83\right.$, $p<0.005)$. These results suggest that OVCR and NOISE had similar effects in hippocampaldependent performance, and that PROG plays a protective role against stress-induced deficit on
FIGURE 3

MWM test results regarding the Frequency of platform-location crossing during consolidation phase

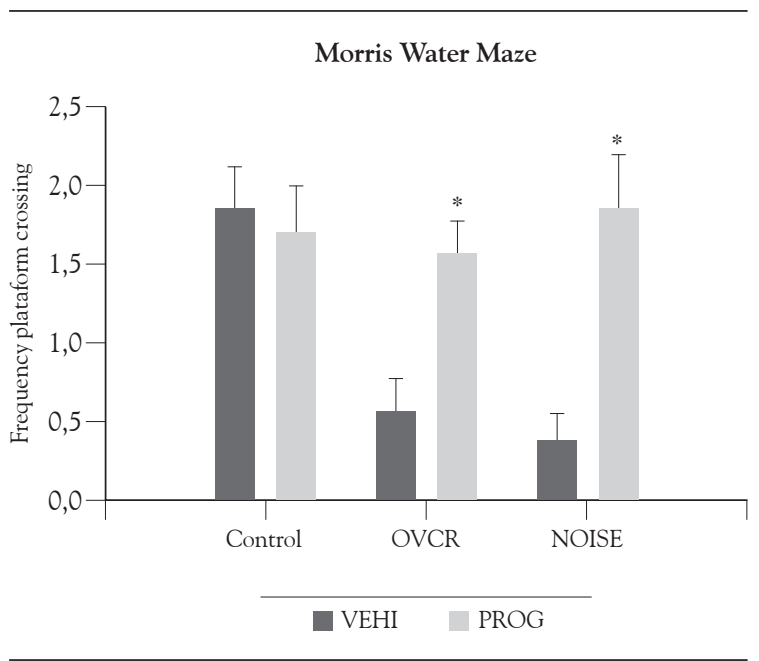

The orientation capacity of VEHI rats exposed to stress in OVCR or NOISE groups was reduced, this limitation was prevented by PROG implants in the other groups of stressed rats; they showed a number of crossings similar to the unstressed control group, indicative of a preserved spatial memory capacity. The bar indicates the standard error. *p $\leq 0.05$.

Source: own work.

consolidation of spatial memory tasks, without affecting this function under ordinary conditions.

\section{Hole board test}

Results were analyzed with the same statistical procedure as the MWM test, and regardless of the stressful situation or implant content they showed no differences, in time spent in central and peripheral zones, mobility or immobility time, visits to central or peripheral holes, and total distance and velocity. However, differences among stress groups $\left(F_{(2,36)}=3.06, p<0.05\right)$ and implants $\left(F_{(1,36)}=2.96, p<0.05\right)$ but not in their interaction $\left(F_{(2,36)}=0.912, p>0.05\right)$, were found for the total number of visits (Figure 3 ). VEHI implanted animals achieved a higher number of total visits (vis.) (37.29 \pm 2.04 vis.) compared to the PROG implanted ( $32.33 \pm 2.13$ vis.), the Bonferroni post hoc test demonstrated that OVCR had no differen- 
ces with Control $(p>0.05)$. Therefore, differences among the types of stress were mainly due to the effect of NOISE stress, which were significantly more effective than Control $(p<0.05)$, but not so more than OVCR $(p>0.05)$. Further one way ANOVA tests were run with implant as a fixed factor, and isolating both stress conditions. In the Control $\left(F_{(1,12)}=0.076, p>0.05\right)$ and OVCR $\left.F_{(1,12)}=0.663, p>0.05\right)$ stress, there were no differences among VEHI and PROG. However, in NOISE stress there was a significant effect of the implant factor $\left(F_{(1,12)}=4.862, p<0.05\right)$, due to VEHI implanted rats showing an increased number of total visits $(45.29 \pm 6.32$ vis.), compared to PROG implanted rats $(35.57 \pm 8.71$ vis.). These results suggest that NOISE but not OVCR, caused an increment of the total number of visits in the hole-board test, and that this effect was inhibited under PROG influence.

\section{FigURE 4}

Number of total visits during hole board test

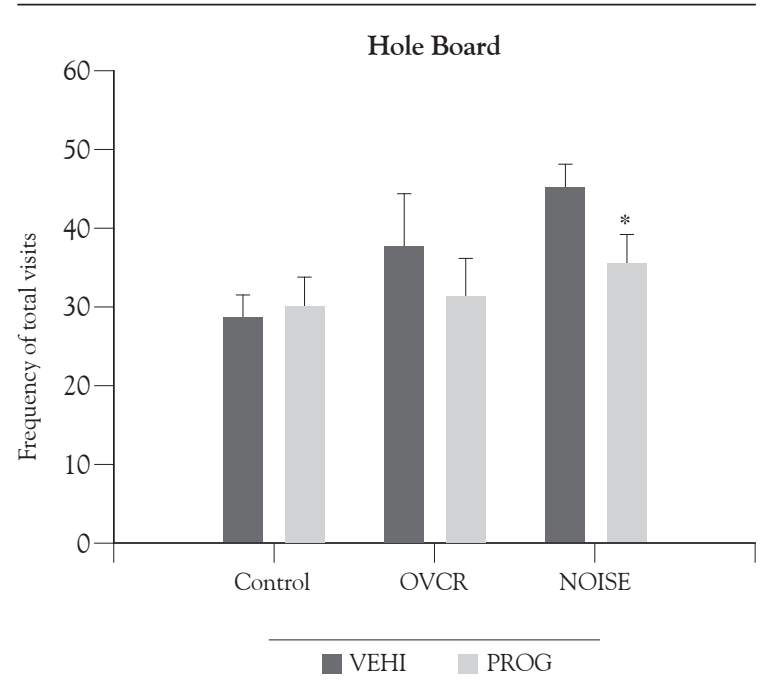

Stressed rats implanted with VEHI showed a significant increase in the number of total visits, especially due to the changes observed in the NOISE group. This stress-induced behavior was significantly reduced in PROG animals exposed to NOISE. However the same tendency can be observed for the PROG animals subjected to OVCR. Bars show standard deviation. ${ }^{*} \mathrm{p} \leq 0.05$.

Source: own work.

\section{Discussion}

In this study, the effect of progesterone vs. vehicle sub-dermic implants on chronic-stress consequences was assessed in Wistar rats. Urinary progesterone and corticosterone levels, spatial memory and exploratory behavior were evaluated in the implanted groups subjected to normal housing, overcrowding or noise stress. To the extent of our knowledge, this is the first in-vivo study, which demonstrated the inhibitory properties of PROG implants on CORT rising, and prevention of spatial memory and exploratory behavior alterations generated by overcrowding or noise stress.

The implants released a constant concentration of PROG as shown by urinary quantification (Figure 1), in which supraphysiological levels (300-400 $\mathrm{ng} / \mu \mathrm{l})$ were sustained throughout the experiment and were not influenced by OVCR or NOISE stress. Urinary measurements were selected not only because they reflect the global amount of the systemic hormone, but also because plasma hormone levels are subjected to greater variability, especially during subject manipulation, which might be inconvenient in a chronic stress experiment. Urinary PROG was undetected in all control and stressed VEHI implanted rats. This does not mean that it is inexistent but that physiological quantities were undetected under the instrument configuration arranged for detection of high levels of implant release. Although other studies have shown an increased intracerebral PROG concentration in response to stress (Shimada \& Yago, 2000) in this study, stress did not affect systemic urinary PROG. However, the high level of PROG liberation must be considered before drawing any conclusions. We also did not quantify the intracerebral concentration of this neurosteroid but its systemic levels. Finally, PROG did not cause a prominent effect on the basal CORT levels in non stressed control rats (Figure 2A). These results support the effectiveness of the long duration silicone implant, demonstrating a high and stable liberation rate that had no secondary effects in normal conditions, at least in the variables assessed, which contradicts 
previous findings where PROG affected control groups (Mediratta et al., 2003).

The quantification of CORT levels is a parameter to determine the magnitude and time course of stress response to different conditions (Bhatnagar \& Vining, 2003). In rats exposed to OVCR, VEHI implanted subjects showed a significant CORT increment, relatively fast when compared with previous OVCR studies (Aioi, Okuda, Matsui, Tonogaito \& Hamada, 2001), this increment was absent in those subjects implanted with PROG (Figure 2B) the latter finding is in agreement with other reports which found that PROG proved to have an inhibitory effect on CORT increase (Higashi et al., 2005). Additionally, PROG has shown an inhibitory effect on stress-induced immunosupression (Mediratta et al., 2003) and neurosteroids like dehydroepiandrosterone demonstrate a protective role against immobilization stress and exogenous CORT (Hu, Cardounel, Gursoy, Anderson \& Kalimi, 2000). This is the first study to show the magnitude, topography and time course of CORT raise due to a chronic social stressor such as overcrowding, more importantly, it clearly shows that supraphysiological PROG levels reached through use of the implants down-regulate this stress-induced rise in CORT elevation.

Previously, artificial USVs have been reported to increase CORT levels (Commissaris et al., 2000). This study found the same effect but then compared it with overcrowding showing a dissimilar CORT time course and magnitude for each stressor (Figures 2B and 2C). Artificial USV's caused a faster, higher and sustained CORT rising compared to OVCR which needed almost one week to have a significantly high CORT rising. No significant difference in the global levels of CORT was found for each type of implants, however, the NOISE group rats, implanted with PROG showed a delayed CORT elevation, followed by a temporary rising that was higher than VEHI group, but subsequently near to the end of the stress period the CORT decreased again, whereas a rapid and sustained CORT rising succeeded in VEHI animals. This delay could be attributed to the inhibitory GABAergic effects of PROG on the HPA axis
(Wu, Gibbs \& Farb, 1991), while normalization could be due to a self-regulation of the HPA axis (after the increase in circulating CORT), together with the PROG inhibitory effects.

The stronger effects of noise stress may be due to the uni-modal characteristics of this stimulus, since the auditory system is fundamental for rodent survival, the neuronal pathway involved in this function is very specific, and for that reason the rats have a limited ability to develop habituation. Noise is closely associated to anxiety manifestations (Beckett, Aspley, Graham \& Marsden, 1996) and USV senerate defensive behaviors (running, jumping and freezing), similar to those biochemical or electrical stimulus in the auditory pathway, at the level of the gray periaqueductal substance and the superior colliculus (Serra et al., 2000).

In contrast, overcrowding causes a polymodal nonspecific sensory stimulation, which could facilitate the physiological and behavioral adaptation, when the animal's survival is not seriously threatened by food and water competition. In our experiment, there was no restriction of water and food, and therefore no confrontations among cage partners, and special attention was given to frequent cage cleaning. Consequently, this stressful situation caused less adverse effects than isolation, immobilization and forced swimming stress. Then the effectiveness of PROG to diminish CORT rises in response to OVCR may be related to a lack of stress stimuli strength. However it is important to consider, that most of human chronic stress occurs in a similar polymodal subtle way in which middle strength stimuli are constantly present (Henry et al., 1993). We and though we are able to deal with them in the beginning, but they end up triggering severe stress responses.

In the MWM test stress did not affect the training but the memory phase. Rats exposed to OVCR or NOISE seemed to be less able to remember where the platform was located during the training trials (Figure 3) these results suggest that the consolidation process was affected, but not the working memory, since every group performed equally during training. This might be due to the fact that a moderated neural over excitation is 
sometimes favorable to facilitate learning under a critical situation, such as escaping from water, but could impair the posterior integrative process between the hippocampus and cerebral cortex to store of information.

Numerous studies have demonstrated that stress produces deficit in memory and spatial learning (de Kloet et al., 2000), however only some studies have utilized chronic stressful situations like those used in this study (Ma, Wang, Yang, Liv \& Chao, 2000) including $105 \mathrm{~dB}$ noise in rats (Arnsten \& Goldman-Rakic, 1998) and recorded traffic noise in humans (Belojević, Ohrström \& Rylander, 1992). This kind of deficit was not showed in the rats with PROG implants, which suggests a protective effect of neurosteroids against behavioral stress responses, at least in memory consolidation processes. This anxiolytic effect has also been observed in several stressful situations (Mediratta et al., 2003), but neither its anti-glucocorticoid effect nor its negative influence on CORT levels had been explored under overcrowding or noise stress. PROG's protective effect is possibly related to CORT inhibition and this is clearer in the OVCR as in the NOISE group in which only retardation in CORT elevation can be observed and a reduction in CORT is barely detected at the end of the stress period. However, behavioral test were done immediately after day 10 of this period, and by then, all rats with PROG implants revealed similar low levels of CORT compared to rats implanted with VEHI. It is therefore conceivable that behavioral effects of PROG implants have been mediated by a reduction in stress-induced CORT.

In the test to evaluate exploratory behavior, the rats exposed to noise showed an increased number of total visits during exploration, but PROG implants inhibited this effect at least significantly in the NOISE group (Figure 4). The increased exploration could be attributed to a motivational component, since mobility and immobility times, distance and velocity were similar for all rats. That means that behavior distribution during the test was different for each group leading to more investment in holes investigation for the stressed rats. Inhibitory effects of PROG could be attributed again to an anxiolytic action which led to a reduction in the CORT levels, - at least for those related to exploratory behavior. In support of our findings, there are studies showing an increased exploration in rats by CORT treatment (Osborn, Kim, Steiger \& Weinberg, 1998). Alternatively, other studies have reported a diminution on exploratory behavior (Aioi et al., 2001; Kovach, Nearing \& Verrier 2001). However they exposed animals to more acute stress with no social characteristics or diffferent models of social stress in distinct species, and with alternative exploration patterns. Most of these experiments utilized the elevated plusmaze and open field to evaluate exploration as an anxiety component. The difference in our results could be due to the fact that the hole-board offers a more enriched and novel stimulating environment for the rats. Finally, although PROG clearly inhibited the increment in exploratory activity in NOISE, for OVCR rats this can only be observed as a trend. Because the hole-board had not been used to evaluate the CORT effects on exploratory behavior before, it could be possible that some of the evaluated parameters are not sensitive enough to show the behavioral manifestations related to CORT levels of rats exposed to OVCR or NOISE at the end of the stress period, when the subjects were tested. There were also no significant differences in the global CORT levels between rats stressed by noise implanted with VEHI or PROG, for this reason is difficult to relate this parameter with the distinct exploratory performance, which could be attributed to an inhibitory action of PROG during the stress period, which diminish the hippocampal alterations.

There are still many questions about the molecular and physiological mechanisms of PROG underlying behavioral stress inhibition and CORT rising. Possible secondary effects derived from the prolonged use of PROG are also unknown. However the results of this study suggest that PROG implants might have an important anxiolytic effect against stress reactions at hormonal and behavioral level. 


\section{References}

Aioi, A., Okuda, M., Matsui, M., Tonogaito, H. \& Hamada, K. (2001). Effect of high population density environment on skin barrier function in mice. Journal of Dermatological Science, 25 (3), 189-197.

Altemus, M., Roca, C., Galliven, E., Romanos, C. \& Deuster, P. (2001). Increased vasopressin and adrenocorticotropin responses to stress in the midluteal phase of the menstrual cycle. The Journal of Clinical Endocrinology and Metabolism, 86 (6), 2525-2530.

Arnsten, A. F. \& Goldman-Rakic, P. S. (1998). Noise stress impairs prefrontal cortical cognitive function in monkeys: Evidence for a hyperdopaminergic mechanism. Archives of General Psychiatry, 55 (4), 362-368.

Beckett, S. R., Aspley, S., Graham, M. \& Marsden, C. A. (1996). Pharmacological manipulation of ultrasound induced defence behaviour in the rat. Psychopharmacology, 127 (4), 384-390.

Belojević, G., Ohrström, E. \& Rylander, R. (1992). Effects of noise on mental performance with regard to subjective noise sensitivity. International Archives of Occupational and Environmental Health, 64 (4), 293-301.

Bhatnagar, S. \& Vining, C. (2003). Facilitation of hypothalamic-pituitary-adrenal responses to novel stress following repeated social stress using the resident/intruder paradigm. Hormones and Behavior, 43 (1), 158-165.

Bodensteiner, K. J., Cain, P., Ray, A. S. \& Hamula, L. A. (2006). Effects of pregnancy on spatial cognition in female Hooded Long-Evans rats. Hormones and Behavior, 49 (3), 303-314. (doi:10.1016/j. yhbeh.2005.08.002)

Commissaris, R. L., Palmer, A., Neophytou, S., Graham, M., Beckett, S. \& Marsden, C. A. (2000). Acoustically elicited behaviours in Lister hooded and Wistar rats. Physiology E Behavior, 68 (4), 521-531.

Frye, C. A., Duffy, C. K. \& Walf, A. A. (2007). Estrogens and progestins enhance spatial learning of intact and ovariectomized rats in the object placement task. Neurobiology of Learning and Memory, 88 (2), 208-216. (doi:10.1016/j.nlm.2007.04.003)
Gulinello, M. \& Smith, S. S. (2003). Anxiogenic effects of neurosteroid exposure: Sex differences and altered GABAA receptor pharmacology in adult rats. The Journal of Pharmacology and Experimental Therapeutics, 305 (2), 541-548. (doi:10.1124/ jpet.102.045120)

Henry, J. P., Liu, Y. Y., Nadra, W. E., Qian, C. G., Mormede, P., Lemaire, V., Ely, D. et al. (1993). Psychosocial stress can induce chronic hypertension in normotensive strains of rats. Hypertension, 21 (5), 714-723.

Higashi, T., Takido, N. \& Shimada, K. (2005). Studies on neurosteroids XVII. Analysis of stress-induced changes in neurosteroid levels in rat brains using liquid chromatography-electron capture atmospheric pressure chemical ionization-mass spectrometry. Steroids, 70 (1), 1-11. (doi:10.1016/j. steroids.2004.08.001)

Hu, Y., Cardounel, A., Gursoy, E., Anderson, P. \& Kalimi, M. (2000). Anti-stress effects of dehydroepiandrosterone: Protection of rats against repeated immobilization stress-induced weight loss, glucocorticoid receptor production, and lipid peroxidation. Biochemical Pharmacology, 59 (7), 753-762.

Juricskay, S. \& Telegdy, E. (2000). Urinary steroids in women with androgenic alopecia. Clinical Biochemistry, 33 (2), 97-101.

Kim, J. J. \& Diamond, D. M. (2002). The stressed hippocampus, synaptic plasticity and lost memories. Nature Reviews Neuroscience, 3 (6), 453-462. (doi:10.1038/nrn849)

Kloet de, E. R., Van Acker, S. A., Sibug, R. M., Oitzl, M. S., Meijer, O. C., Rahmouni, K., \& de Jong, W. (2000). Brain mineralocorticoid receptors and centrally regulated functions. Kidney International, 57 (4), 1329-1336. (doi:10.1046/j.1523. 1755.2000.00971.x)

Kovach, J. A., Nearing, B. D. \& Verrier, R. L. (2001). Angerlike behavioral state potentiates myocardial ischemia-induced $\mathrm{T}$-wave alternans in canines. Journal of the American College of Cardiology, 37 (6), 1719-1725.

Kuhlmann, S. \& Wolf, O. T. (2005). Cortisol and memory retrieval in women: Influence of menstrual cycle and oral contraceptives. Psychopharmacology, 183 (1), 65-71. (doi:10.1007/s00213-005-0143-z) 
Le Mellédo, J. \& Baker, G. (2004). Role of progesterone and other neuroactive steroids in anxiety disorders. Expert Review of Neurotherapeutics, 4 (5), 851 860. (doi:10.1586/14737175.4.5.851)

Lordi, B., Patin, V., Protais, P., Mellier, D. \& Caston, J. (2000). Chronic stress in pregnant rats: Effects on growth rate, anxiety and memory capabilities of the offspring. International Journal of Psychophysiology: Official Journal of the International Organization of Psychophysiology, 37 (2), 195-205.

Ma, Q., Wang, J., Yang, Z. H., Liv, H. T. \& Chao, F. H. (2000). [Effects of chronic stress on the learning and memory ability and hippocampal LTP in rats]. Zhongguo Ying Yong Sheng Li Xue Za Zhi = Zhongguo Yingyong Shenglixue Zazhi = Chinese Journal of Applied Physiology, 16 (4), 318-320.

Magariños, A. M., Verdugo, J. M. \& McEwen, B. S. (1997). Chronic stress alters synaptic terminal structure in hippocampus. Proceedings of the $\mathrm{Na}$ tional Academy of Sciences of the United States of America, 94 (25), 14002-14008.

Maki, P. M., Zonderman, A. B. \& Resnick, S. M. (2001). Enhanced verbal memory in nondemented elderly women receiving hormone-replacement therapy. The American Journal of Psychiatry, 158 (2), 227-233.

Maurice, T., Urani, A., Phan, V. L. \& Romieu, P. (2001). The interaction between neuroactive steroids and the sigmal receptor function: Behavioral consequences and therapeutic opportunities. Brain Research. Brain Research Reviews, 37 (1-3), 116-132.

McEwen, B. S. (2000). Effects of adverse experiences for brain structure and function. Biological Psychiatry, 48 (8), 721-731.

McGaugh, J., Cahill, L., Parent, M., Mesches, M., Coleman-Mesches, K. \& Salinas, J. (1995). Involvement of the amygdala in the regulation of memory storage. In J. L. McGaugh, F. Bermudez-Rattoni \& R. A.Prado-Alcala (Eds.), Plasticity in the central nervous system: Learning and memory (pp. 18-39). Hillsdate, NJ: Erlbaum.

Mediratta, P. K., Bhatia, J., Tewary, S., Katyal, V., Mahajan, P. \& Sharma, K. K. (2003). Attenuation of the effect of progesterone and 4'-chlordiazepam on stress-induced immune responses by bicuculline.
Indian Journal of Physiology and Pharmacology, 47 (3), 288-296.

Obut, T. A., Ovsyukova, M. V. \& Cherkasova, O. P. (2004). Ratio between the contents of 11-dehydrocorticosterone and corticosterone after acute and repeated stress: Effect of dehydroepiandrosterone sulfate. Bulletin of Experimental Biology and Medicine, 138 (2), 137-139.

Osborn, J. A., Kim, C. K., Steiger, J. \& Weinberg, J. (1998). Prenatal ethanol exposure differentially alters behavior in males and females on the elevated plus maze. Alcoholism, Clinical and Experimental Research, 22 (3), 685-696.

Quervain de, D. J., Roozendaal, B. \& McGaugh, J. L. (1998). Stress and glucocorticoids impair retrieval of long-term spatial memory. Nature, 394 (6695), 787-790. (doi:10.1038/29542)

Raber, J. (1998). Detrimental effects of chronic hypothalamic-pituitary-adrenal axis activation. From obesity to memory deficits. Molecular Neurobiology, 18 (1), 1-22. (doi:10.1007/BF02741457)

Reddy, D. S., O’Malley, B. W. \& Rogawski, M. A. (2005). Anxiolytic activity of progesterone in progesterone receptor knockout mice. Neuropharmacology, 48 (1), 14-24. (doi:10.1016/j. neuropharm.2004.09.002)

Rhodes, M. E. \& Frye, C. A. (2005). Attenuating 5alpha-pregnane-3alpha-ol-20-one formation in the hippocampus of female rats increases pentylenetetrazole-induced seizures. Epilepsy \& Behavior: $E \& B, 6$ (2), 140-146. (doi:10.1016/j.yebeh.2004.11.019)

Serra, M., Pisu, M. G., Littera, M., Papi, G., Sanna, E., Tuveri, F., Usala, L. et al. (2000). Social isolation-induced decreases in both the abundance of neuroactive steroids and GABA(A) receptor function in rat brain. Journal of Neurochemistry, 75 (2), 732-740.

Shimada, K. \& Yago, K. (2000). Studies on neurosteroids X. Determination of pregnenolone and dehydroepiandrosterone in rat brains using gas chromatography-mass spectrometry-mass spectrometry. Journal of Chromatographic Science, 38 (1), 6-10.

Sipos, M. L. \& Nyby, J. G. (1996). Concurrent androgenic stimulation of the ventral tegmental area 
and medial preoptic area: Synergistic effects on male-typical reproductive behaviors in house mice. Brain Research, 729 (1), 29-44.

Türkmen, S., Löfgren, M., Birzniece, V., Bäckström, T. \& Johansson, I. (2006). Tolerance development to Morris water maze test impairments induced by acute allopregnanolone. Neuroscience, 139 (2), 651-659. (doi:10.1016/j.neuroscience.2005.12.031)

Vallée, M., Rivera, J. D., Koob, G. F., Purdy, R. H. \& Fitzgerald, R. L. (2000). Quantification of neurosteroids in rat plasma and brain following swim stress and allopregnanolone administration using negative chemical ionization gas chromatography/ mass spectrometry. Analytical Biochemistry, 287 (1), 153-166. (doi:10.1006/abio.2000.4841)

Wu, F. S., Gibbs, T. T. \& Farb, D. H. (1991). Pregnenolone sulfate: A positive allosteric modulator at the N-methyl-D-aspartate receptor. Molecular Pharmacology, 40 (3), 333-336.

Zuluaga, M. J., Agrati, D., Pereira, M., Uriarte, N., Fernández-Guasti, A. \& Ferreira, A. (2005). Experimental anxiety in the black and white model in cycling, pregnant and lactating rats. Physiology ES Behavior, 84 (2), 279-286. (doi:10.1016/j.physbeh.2004.12.004). 